\title{
Changing prevalence and the risk factors for antenatal obstetric hospitalizations in Denmark 2003-20I2
}

This article was published in the following Dove Press journal:

Clinical Epidemiology

II June 2016

Number of times this article has been viewed

\author{
Jane Bendix' \\ Hanne Kristine Hegaard ${ }^{2}$ \\ Jens Langhoff-Roos ${ }^{3}$ \\ Thomas Bergholt ${ }^{3}$ \\ 'Department of Gynaecology and \\ Obstetrics, Nordsjaellands Hospital \\ Hillerod, University of Copenhagen, \\ Hillerod, Denmark; ${ }^{2}$ The Research \\ Unit of Women's and Children's \\ Health, The Juliane Marie Centre for \\ Women, Children and Reproduction, \\ Rigshospitalet, University of \\ Copenhagen, Copenhagen, Denmark; \\ ${ }^{3}$ Department of Obstetrics, The \\ Juliane Marie Centre, Rigshospitalet, \\ University of Copenhagen, \\ Copenhagen, Denmark
}

Purpose: Population-based studies evaluating the use and extent of antenatal obstetric hospitalizations $(\mathrm{AOH})$ are sparse. The objective of the present study was to describe the prevalence, time trend, and risk factors for $\mathrm{AOH}$ in Denmark.

Materials and methods: A retrospective national register-based cohort study was conducted that included all pregnancies with delivery after 22 gestational weeks in Denmark from 2003 to 2012. The outcomes were $\mathrm{AOH}$ and the diagnoses leading to these hospitalizations. AOH was defined as an antenatal hospitalization for at least 1 day with at least one obstetric International Classification of Diseases-10 diagnosis and admission date more than 3 days before delivery. Results: The study included 617,906 pregnancies; 48,366 (7.8\%) pregnancies were associated with 64,072 $\mathrm{AOH}$ before delivery. The percentage of pregnancies with $\mathrm{AOH}$ decreased from $8.6 \%$ to $7.1 \%$. The median length of stay decreased from 3 to 2 days, and admission for at least 7 days was almost halved. Threatened preterm delivery was the most frequent diagnostic category for $\mathrm{AOH}$. A decline was seen in all diagnostic categories except maternal diseases. Significant risk factors for $\mathrm{AOH}$ were multiple pregnancies, low or high maternal age and body mass index, nulliparity, lower educational levels, unemployment or being outside the workforce, single partner status, and smoking. The relative risk of very preterm delivery before gestational age of 34 weeks was higher in pregnancies with $\mathrm{AOH}$ compared with pregnancies without $\mathrm{AOH}$ (relative risk 15.2; 95\% confidence interval: 14.6-15.8).

Conclusion: This study shows a shift toward less use and shorter duration of antenatal hospitalization in Denmark. The most common indication used in pregnancies with $\mathrm{AOH}$ was threatened preterm delivery, and more than one-third resulted in very preterm deliveries.

Keywords: obstetric admissions, pregnancy complications, diagnosis, Danish health registry study, time trend

\section{Introduction}

Pregnancy complications, such as threatened preterm delivery, antenatal hemorrhage, hypertensive disorders, severe vomiting, and diabetes, may lead to antenatal hospitalization. ${ }^{1-4}$ Previous observational studies identified young maternal age, ethnicity, living in areas with low socioeconomic status, and geographic placement of the admitting hospital as risk factors for antenatal hospital admissions. ${ }^{1-4}$

Antenatal hospitalizations may be offered, so that a thorough evaluation can be performed or for increased fetal or maternal surveillance to detect any deterioration in the maternal or fetal condition that may necessitate medical interventions or lead to delivery. ${ }^{3,5,6}$ Hospitalization may also be used to restrict the pregnant women's physical activity, which is traditionally considered beneficial despite the lack of evidence to
Correspondence: Jane Bendix Department of Gynaecology and Obstetrics, Nordsjaellands Hospital, Hillerod, Dyrehavevej 29, G0I I I, 3400 Hillerod, Denmark Tel +45 48296443

Email Jane.Bendix@regionh.dk 
support the recommendation of strict activity restriction in high-risk pregnancies to prevent impending preterm delivery. ${ }^{7-13}$ In addition, antenatal hospitalization with strict activity restriction may cause stressful adverse effects for the pregnant woman and her family and may deteriorate health in general as well as maternal health during pregnancy. ${ }^{11,14-20}$ On the other hand, there is an increasing focus on the benefits of physical activity during pregnancy. ${ }^{21-23}$

In clinical practice, such hospitalizations seem to have decreased in Canada over the previous decades. ${ }^{4}$ However, little is known about the use of antenatal hospitalization in Denmark before delivery.

In the present study, we describe the prevalence and time trend in the use of antenatal obstetric hospitalizations $(\mathrm{AOH})$ in pregnancies associated with hospitalization for different groups of diagnoses. Furthermore, our aim was to identify risk factors for antenatal hospitalizations as well as the risk of very preterm delivery in pregnancies associated with $\mathrm{AOH}$.

\section{Materials and methods}

The study was designed as a retrospective, national, registerbased cohort study linking information from four national health registers.

\section{Study population}

The study population included pregnancies resulting in deliveries at or later than 22 completed gestational weeks or in live-born babies at shorter gestational ages in Denmark between January 1, 2003 and December 31, 2012. Pregnancies with unknown gestational age at delivery were excluded. Gestational age was generally calculated on the basis of a first-trimester ultrasound examination.

\section{National health registers}

From the National Registry of Patients, we obtained individual data, with dates for admission and discharge, discharge diagnoses, and other information concerning each $\mathrm{AOH} .{ }^{24}$ The National Registry of Patients has collected all information for all individual patient-related contacts with the Danish hospital services since 1977, including admissions, ambulatory treatments, and outpatient management. Hospitalizations are registered with discharge diagnoses classified according to the World Health Organization's International Classification of Diseases (ICD) (ICD-10 since 1994). ${ }^{25}$ Diagnoses are sorted hierarchically by a primary action diagnosis and possible secondary diagnoses.

Since 1973, the Danish Medical Birth Registry has registered all live and stillbirths with information on conditions and interventions during pregnancies for deliveries after 22 weeks of gestation were completed or earlier if the baby was live born.

Statistics Denmark registers sociodemographic information on all citizens in Denmark and is updated yearly.

The Central Person Register includes a unique 10-digit personal identification number issued to all Danish citizens at birth, upon immigration, or to residents living in Denmark for longer than 3 months. The personal identification number for each pregnant woman was used to link data from the National Registry of Patients with data from the Danish Medical Birth Registry and Statistics Denmark. ${ }^{24}$ Personal anonymity and confidentiality were strictly preserved as every personal identification number was replaced by a unique 12-digit encrypted, nontraceable number prior to the retrieval of data.

\section{Variables}

From the registers, we obtained the following pregnancy characteristics and perinatal data: maternal age at delivery, parity, plurality, pregravid body mass index (BMI), maternal education level, working status the year before delivery, smoking status during pregnancy, and partner status. To describe the outcome of $\mathrm{AOH}$ pregnancies, we obtained gestational age at delivery, Apgar score, stillbirths, perinatal deaths, neonate admissions at the neonatal intensive care unit, and neonatal deaths. We defined very preterm delivery as delivery before completing 34 gestational weeks.

\section{Outcome}

In the $\mathrm{AOH}$ group, we included all pregnant women hospitalized with at least one obstetric ICD-10 diagnosis (Chapter XV) for at least 1 day in an obstetric department with admission date more than 3 days before the date of delivery. ${ }^{25}$

Each $\mathrm{AOH}$ was registered from admission date to discharge date, and the length of stay was calculated by subtracting these two dates. If a woman was readmitted with more than 1 day in between, these were registered as separate admissions. If a woman was discharged followed by a new admission on the same day at the same or another obstetric department, this was registered as one continuous admission.

\section{The main diagnostic categories}

To describe the AOHs, we created 14 main diagnostic categories that included both relevant primary action diagnosis and possible secondary diagnoses. The 14 main diagnostic categories are presented in Table 1. 
Table I Main diagnostic categories of $\mathrm{AOH}$

\begin{tabular}{|c|c|}
\hline Main diagnostic categories & $\begin{array}{l}\text { Discharge diagnosis codes } \\
\text { (ICD-10) }\end{array}$ \\
\hline $\begin{array}{l}\text { I. Threatened preterm } \\
\text { delivery }\end{array}$ & O34, O42, O47, O60 \\
\hline 2. Hemorrhage & O20, O46 \\
\hline 3. Placental disorders & O43, O44, O45 \\
\hline 4. Amniotic fluid disorders & O40, O4I \\
\hline $\begin{array}{l}\text { 5. Genitourinary tract } \\
\text { infections }\end{array}$ & $\mathrm{O} 23$ \\
\hline 6. Fetus-related complications & $\mathrm{O} 35, \mathrm{O} 36$ \\
\hline $\begin{array}{l}\text { 7. Complications specific to } \\
\text { multiple gestations }\end{array}$ & O30, О3I \\
\hline 8. Venous complications & $\mathrm{O} 22$ \\
\hline 9. Molimina & $\mathrm{O} 21, \mathrm{O} 25, \mathrm{O} 26$ \\
\hline $\begin{array}{l}\text { 10. Edema, proteinuria, and } \\
\text { hypertensive disorders }\end{array}$ & OI0, OII, OI2, OI3, OI4, OI5, OI6 \\
\hline II. Diabetes & $\mathrm{O} 24$ \\
\hline 12. Maternal diseases & 099 \\
\hline 13. Other diagnoses & O28, O29, O32, O33, O88, O9।, O98 \\
\hline $\begin{array}{l}\text { 14. Delivery diagnoses } \\
\text { (if } \mathrm{AOH} \text { resulted in delivery) }\end{array}$ & O80, О8I, О82, О83, О84 \\
\hline
\end{tabular}

Abbreviations: $\mathrm{AOH}$, antenatal obstetric hospitalizations; ICD-10, International Classification of Diseases-10.

In addition, we obtained selected subgroup diagnoses of the diagnostic category, threatened preterm delivery: threatened preterm birth, O472; contractions at $<37$ weeks, O470, O600; clinical cervical incompetence, O343A; ultrasonic cervical incompetence, O343B, O348G; and preterm prelabor rupture of membranes, $\mathrm{O} 42$. We registered how many different discharge diagnoses described the course of each $\mathrm{AOH}$.

\section{Statistical methods}

We calculated temporal trends of antenatal hospitalizations as prevalence, and examined the univariate associations between risks of antenatal hospitalizations and a priori defined biologically plausible independent risk factors (maternal age, parity, plurality, BMI, education level, working status the year before delivery, smoking status, and partner status) using binominal logistic regression. Subsequently, we performed a multivariate logistic regression model with mutual adjustment for the independent risk factors and year of admission. The estimates were reported as odds ratios (ORs) with $95 \%$ confidence intervals (CIs).

All analyses were performed using SPSS statistical software version 19 (IBM, Corp., Copenhagen, Denmark, Europe).

\section{Ethical approval}

The Danish Data Protection Agency (J.nr. 2012-41-0009) and the Danish Health and Medicines Authority (J.nr. 3-3013-8/1/EHE) both approved the study. Notification of the study was given to a regional committee on biomedical research ethics (P.nr. H-2-2011-130); ethical approval is not required for registry-based studies in Denmark.

\section{Results}

\section{Time trends of $\mathrm{AOH}$}

Overall, there were 617,906 pregnancies with deliveries at or later than 22 completed gestational weeks or with liveborn babies at shorter gestational ages in Denmark between January 1, 2003 and December 31, 2012. The rate of such pregnancies declined $12 \%$, from 63,328 pregnancies during the initial study year to 55,963 pregnancies in the final year (Table 2). Of the overall pregnancies, 48,366 had 64,072 AOHs before delivery (Tables 2 and 3 ).

The overall frequency time trend of pregnancies with AOHs is shown in Figure 1. Of the overall pregnancies, the rate of these with one or more $\mathrm{AOH}$ was $7.8 \%(48,366 / 617,906)$, with a steady reduction of $17 \%$, from $8.6 \%(5,449 / 63,328)$ in 2003 to $7.1 \%(3,983 / 55,963)$ in 2012. The characteristics of pregnancies with $\mathrm{AOH}$ are summarized in Table 2.

The total number of $\mathrm{AOH}$ declined by $25 \%$, from 7,158 admissions in 2003 to 5,393 admissions in 2012 (Table 3). The median length of in-hospital stays decreased during the study period from 3 to 2 days. The frequency of hospitalizations with duration of 7 days or more was reduced by $46 \%$, from 2,318 to 1,263 (Table 3). The mean number of diagnostic categories for each $\mathrm{AOH}$ increased from 1.1 to 1.4 during the study period (data not shown).

\section{Time trends of $\mathrm{AOH}$ and very preterm delivery}

The prevalence of very preterm delivery per 100 pregnancies was $1.5 \%$ in the study population $(9,157 / 617,906)$, whereas the rate of very preterm delivery after $\mathrm{AOH}$ per 100 pregnancies was $0.6 \%(3,922 / 617,906)$ (Table 2$)$. These prevalences remained relatively constant during the study period. In pregnancies with $\mathrm{AOH}$, the prevalence of very preterm delivery increased from $6.9 \%$ to $9.2 \%$ (Table 2). Of the overall very preterm deliveries, more than one-third occurred in pregnancies with $\mathrm{AOH}$, and the proportion increased from $40 \%$ to $44 \%$ during the study period (Table 2 ).

The very preterm delivery and perinatal outcomes as results of pregnancies with $\mathrm{AOH}$ are summarized in Table 2.

\section{Diagnostic categories for $\mathrm{AOH}$}

The diagnostic categories for $\mathrm{AOH}$ are shown in Figure 2. Sixty-seven percent of the overall AOHs were registered by diagnoses in only one diagnostic category (data not shown). 


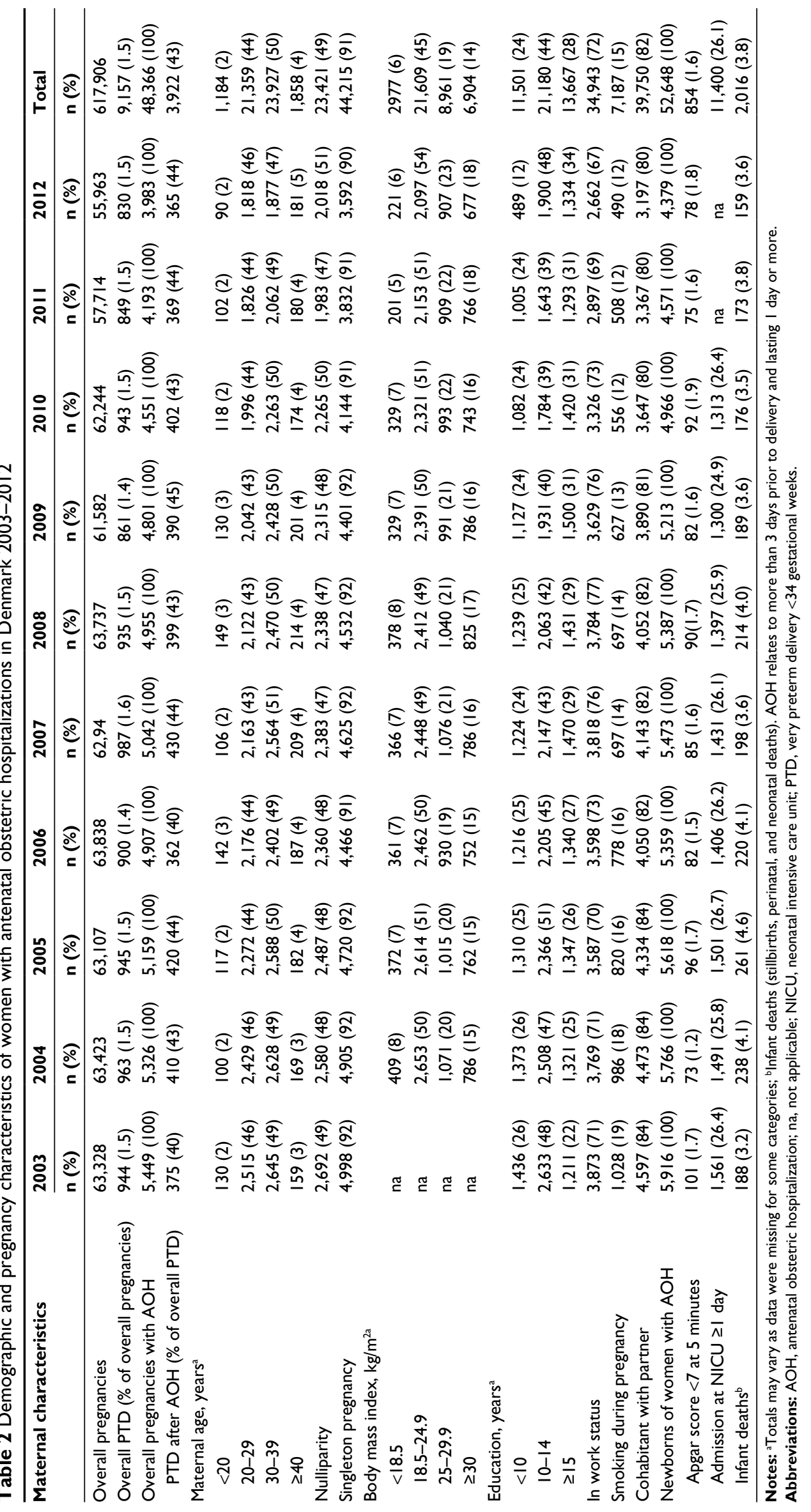


Table 3. Antenatal obstetric hospitalizations in Denmark 2003-20I2

\begin{tabular}{|c|c|c|c|c|c|c|c|c|c|c|c|}
\hline \multirow{2}{*}{$\begin{array}{l}\text { Antenatal obstetric } \\
\text { hospitalizations }\end{array}$} & 2003 & 2004 & 2005 & 2006 & 2007 & 2008 & 2009 & 2010 & 2011 & 2012 & Total \\
\hline & n (\%) & n (\%) & n (\%) & n (\%) & n (\%) & n (\%) & n (\%) & n (\%) & n (\%) & n (\%) & n (\%) \\
\hline \multirow[t]{2}{*}{ Total $\mathrm{AOH}$} & 7,158 & 7,031 & 6,793 & 6,519 & 6,596 & 6,604 & 6,395 & 6,067 & 5,516 & 5,393 & $\overline{64,072}$ \\
\hline & $(100)$ & $(100)$ & $(100)$ & $(100)$ & $(100)$ & $(100)$ & $(100)$ & $(100)$ & $(100)$ & $(100)$ & $(100)$ \\
\hline \multirow[t]{2}{*}{ Discharge before delivery } & 5,609 & 5,496 & 5,261 & 5,187 & $5,|4|$ & 5,201 & 5,095 & 4,887 & 4,550 & 4,460 & 50,887 \\
\hline & (78) & $(78)$ & (77) & $(80)$ & $(78)$ & (79) & $(80)$ & $(8 I)$ & $(82)$ & $(83)$ & (79) \\
\hline \multirow[t]{2}{*}{ In-hospital stays $\geq 7$ days } & 2,318 & 2,158 & 2,069 & 1,902 & 1,898 & 1,800 & I,755 & 1,610 & 1,354 & 1,263 & 18,127 \\
\hline & (32) & (34) & (33) & (30) & $(30)$ & $(28)$ & (29) & (26) & (24) & $(23)$ & (29) \\
\hline $\begin{array}{l}\text { Length of "in-hospital stays" } \\
\text { (median days) }\end{array}$ & $3(1 ; 17)$ & $3(1 ; 17)$ & $3(1 ; 16)$ & $2(1 ; 16)$ & $2(1 ; 16)$ & $2(1 ; 15)$ & $2(1 ; 16)$ & $2(1 ; 16)$ & $2(1 ; 16)$ & $2(1 ; 14)$ & $2(1 ; 16)$ \\
\hline
\end{tabular}

Note: ${ }^{a}$ Median ( 10 percentile; 90 percentile).

Abbreviation: $\mathrm{AOH}$, antenatal obstetric hospitalizations.

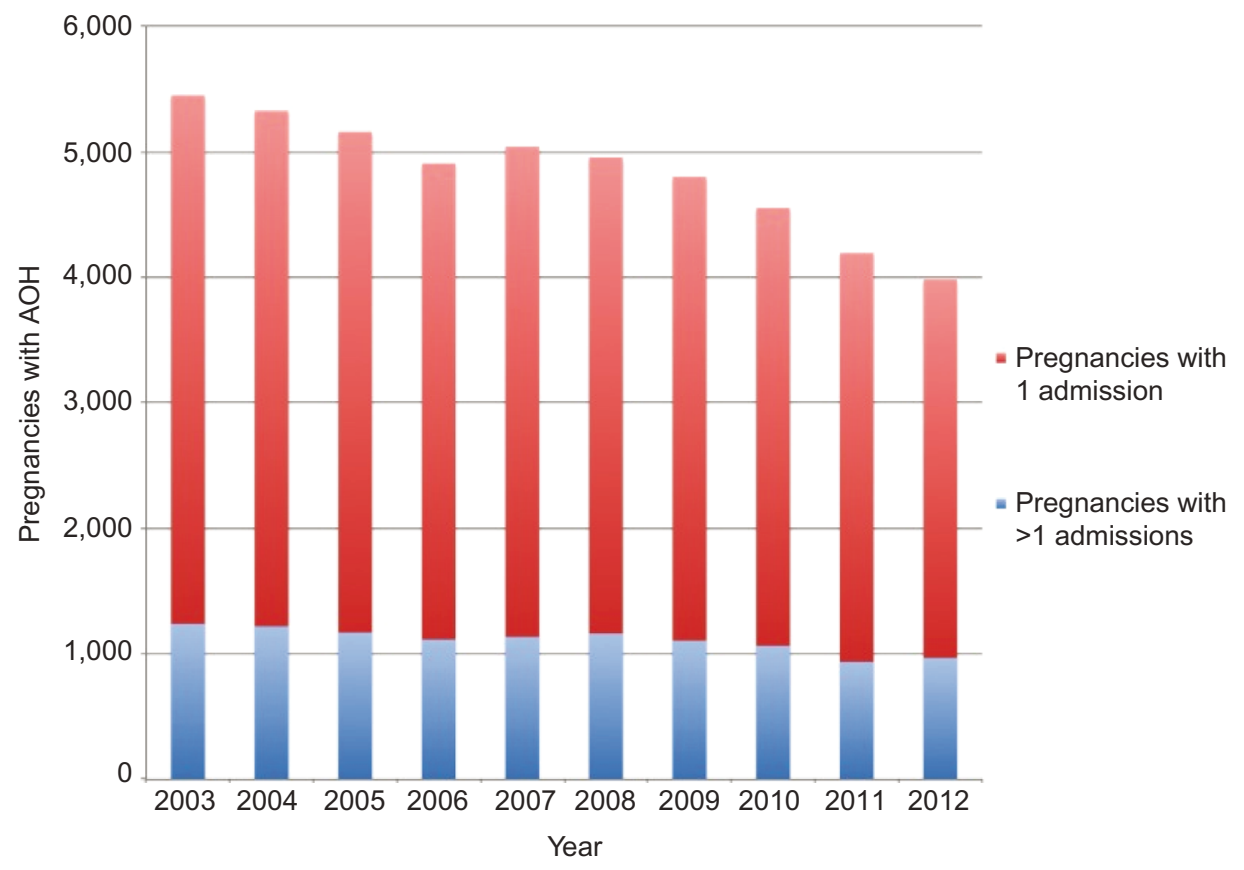

Figure I Pregnancies associated with AOH in Denmark 2003-20I2.

Abbreviation: $\mathrm{AOH}$, antenatal obstetric hospitalizations.

The five most frequent diagnostics categories associated with $\mathrm{AOH}$ during the study period were threatened preterm delivery, maternal diseases, molimina, delivery, edema, proteinuria, and hypertensive disorders (Figure 2). All diagnostic categories showed a decline except maternal diseases, which increased by $145 \%$, from 660 hospitalizations in 2003 to 1,616 in 2012 (Figure 2).

The most frequent diagnostic category was threatened preterm delivery, explaining the $15 \%(318 / 2,048)$ decrease in $\mathrm{AOH}$ during the study period (Figure 2). Of all the pregnancies, $2.6 \%(15,823 / 617,906)$ had a history of $\mathrm{AOH}$ within the diagnostic category "threatened preterm" delivery. Of these pregnancies, $14.9 \%(2,363 / 15,823)$ resulted in a very preterm delivery (data not shown). The overall rate of the selected subdiagnoses in the threatened preterm delivery diagnostic category decreased by $16 \%$, from 1,779 at the start of the study to 1,499 at the end of the study. The threatened preterm birth and the preterm prelabor rupture of membranes subdiagnoses decreased, whereas the diagnoses of clinical cervical incompetence, ultrasonic cervical incompetence, and contractions at $<37$ gestational weeks all increased (Figure 3).

\section{Subanalysis of the diagnostic category "maternal diseases"}

Because the diagnostic category "maternal diseases" was the only category that increased, we did a subanalysis of $\mathrm{AOH}$, including those with a single diagnostic category (67\%). 


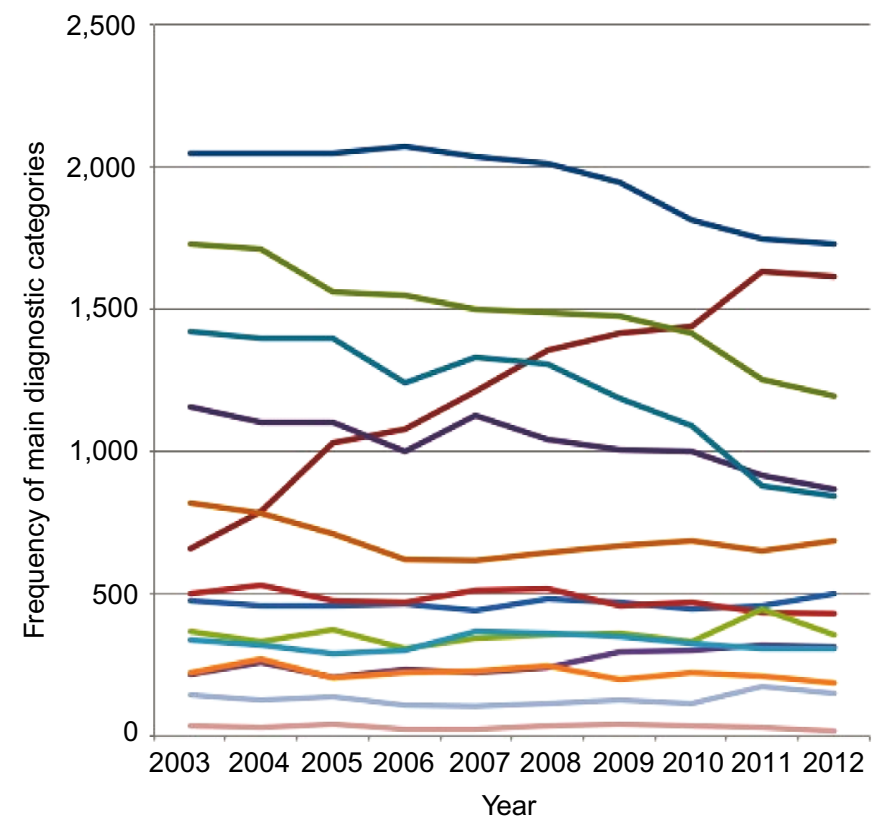

- Threatened preterm delivery

- Maternal diseases

- Molimina

- Edema, proteinuria, and hypertensive disorders

- Delivery diagnoses

- Hemorrhage

- Complications specific to multiple gestations

- Genitourinary tract infections

- Fetus-related complications

- Placental disorders

- Diabetes

- Other diagnoses

- Amniotic fluid disorders

— Venous complications

Figure 2 Main diagnostic categories of AOH in Denmark 2003-2012.

Abbreviation: $\mathrm{AOH}$, antenatal obstetric hospitalizations.

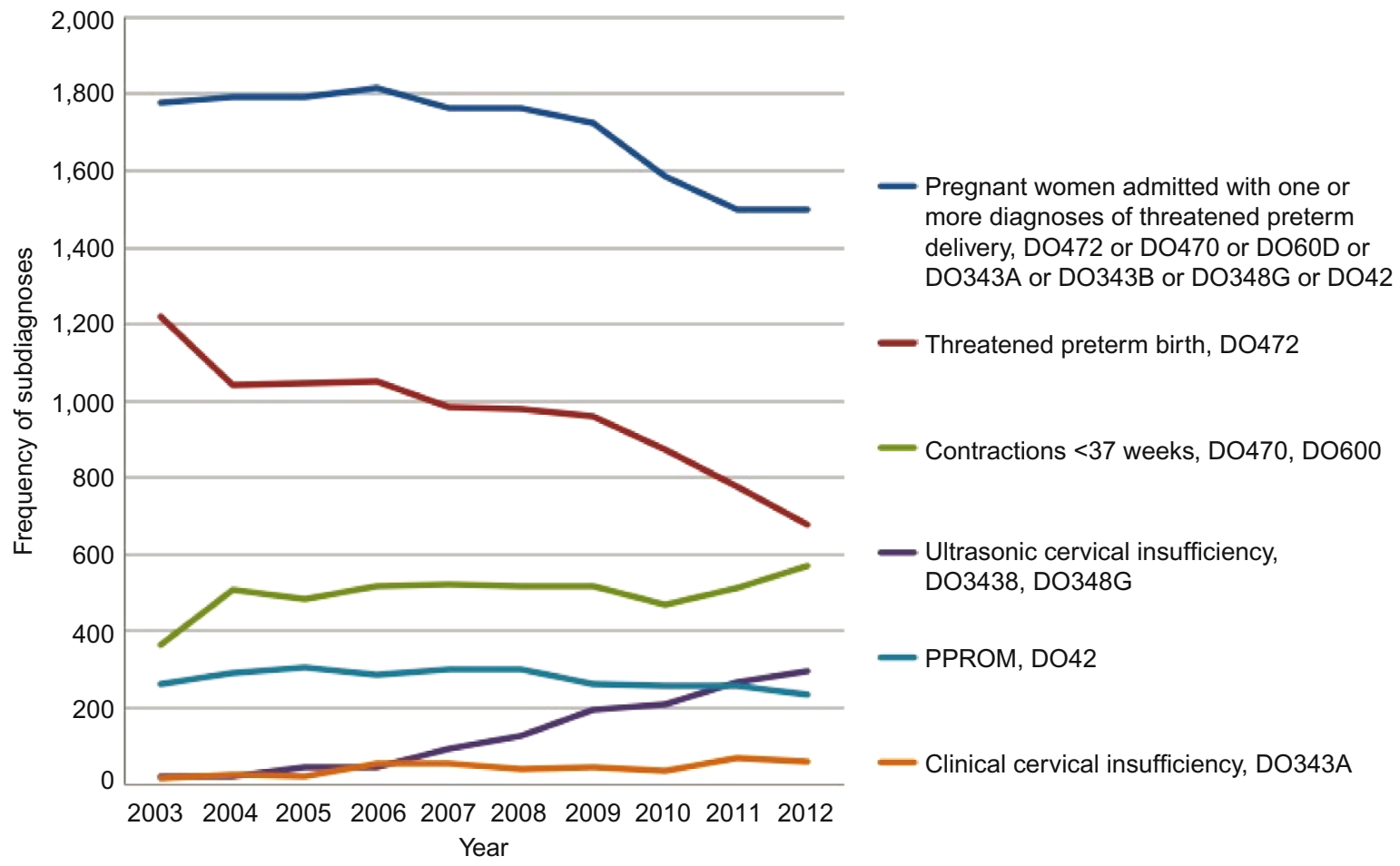

Figure $3 \mathrm{AOH}$ with threatened preterm delivery in Denmark 2003-20I2.

Abbreviations: $\mathrm{AOH}$, antenatal obstetric hospitalizations; PPROM, preterm premature rupture of membranes.

The five most frequent categories were molimina, threatened preterm delivery, maternal diseases, edema, proteinuria, and hypertensive disorders, and hemorrhage. The number of $\mathrm{AOH}$ only categorized as maternal diseases increased by $157 \%$, from 182 hospitalizations in 2003 to 467 in 2012, in contrast to decreases in all the other diagnostic categories (Figure 4).

In pregnancies with $\mathrm{AOH}$ for maternal diseases with or without other diagnostic groups, the increased registration 


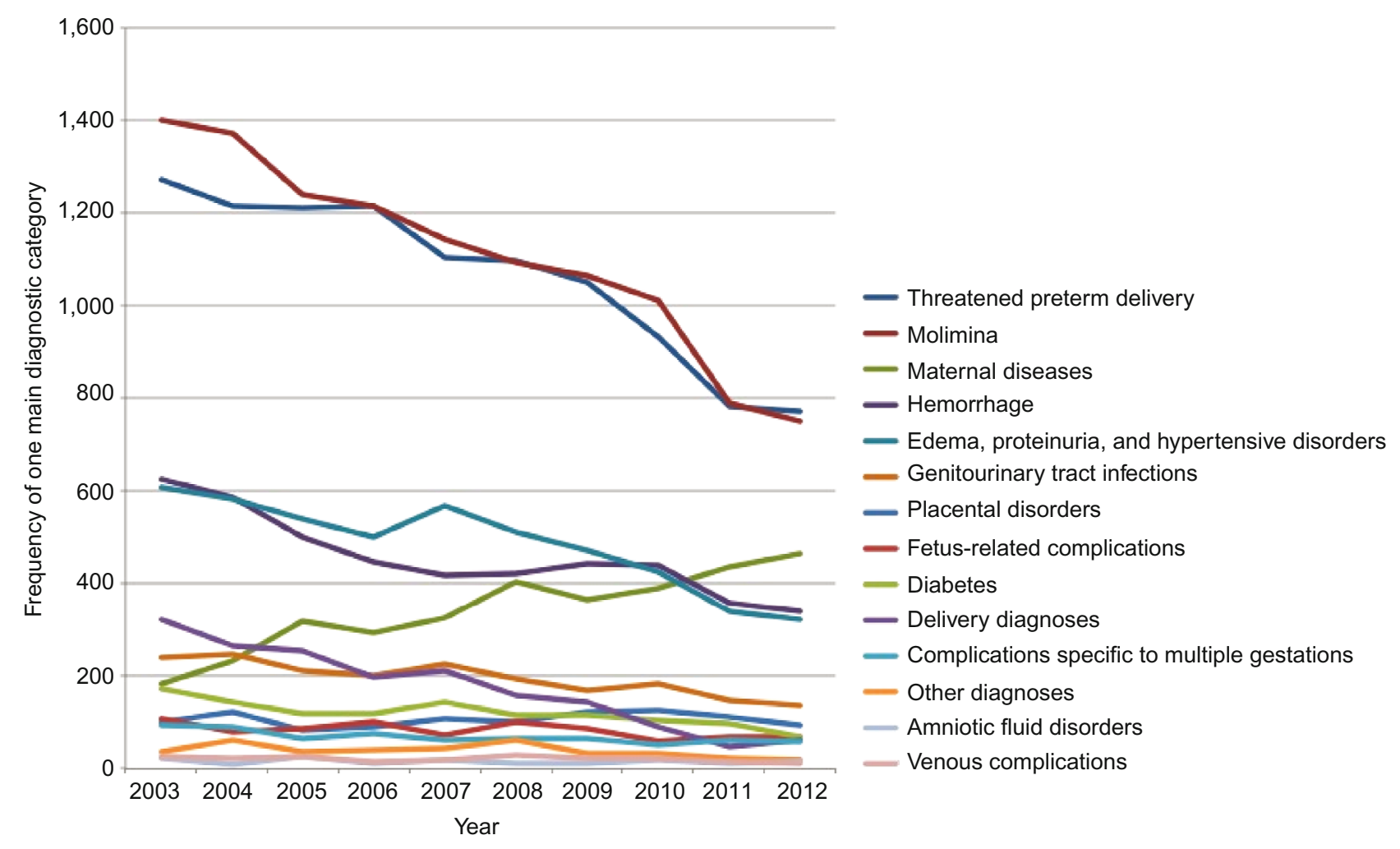

Figure $4 \mathrm{AOH}$ with one main diagnostic category in Denmark 2003-20I2.

Abbreviation: $\mathrm{AOH}$, antenatal obstetric hospitalizations.

of the diagnostic codes for maternal diseases was explained by the nonspecific subcode, O99.8 (diagnoses linked to the O99 diagnoses) in $66 \%(8,014 / 12,244)$ of cases (data not shown).

\section{Risk of $\mathrm{AOH}$}

Finally, in Table 4, we calculate the risk of $\mathrm{AOH}$ in pregnancies. The adjusted risk was increased in multiple pregnancies (OR: 5.5; 95\% CI: 5.3-5.7). The risk of $\mathrm{AOH}$ according to maternal age demonstrated a U-shaped increase, with the highest risk for women younger than 20 years (OR: 1.22; 95\% CI: $1.13-1.32$ ) and women aged 40 years or older (OR: 1.48; 95\% CI: 1.39-1.57). The same pattern was seen with BMI, where women with a BMI lower than $18.5 \mathrm{~kg} / \mathrm{m}^{2}$ (OR: 1.26 ; $95 \%$ CI: $1.20-1.31$ ) or higher than $29.9 \mathrm{~kg} / \mathrm{m}^{2}$ (OR: 1.56; 95\% CI: 1.51-1.60) had the most increased risk. In pregnancies with maternal education level less than 15 years, the risk of AOH increased inversely. Furthermore, the risk increased in pregnancies of nulliparity, of those outside the workforce, of those with a single partner status, and of maternal smokers (Table 4).

In pregnancies with $\mathrm{AOH}$, the crude relative risk (RR) of very preterm delivery before 34 gestational weeks was increased compared with pregnancies without AOH (RR: 15.2; 95\% CI: 14.6-15.8) (data not shown).

\section{Discussion}

The results of this nationwide, population-based cohort study show a temporal decrease of $17 \%$ in $\mathrm{AOH}$, a mean reduction from 3 to 2 days in in-hospital stays and a 15-fold increased risk of preterm delivery in pregnancies associated with $\mathrm{AOH}$. The findings may indicate a shift in clinical practice toward outpatient management of pregnancy-related complications. The antenatal hospitalization rate during the study period was lower than that previously reported in the USA and Canada, which could reflect differences in health care systems, educational programs, and services. ${ }^{3,4}$ The Danish health care system is public and free of charge, and $99 \%$ of pregnant women participate in the antenatal care program. ${ }^{26}$ In Canada, easy accessibility of maternity care differs by rural versus urban areas of each province or territory, whereas a public, free-of-charge antenatal care program similar to that in Denmark is not available in the $\mathrm{USA}^{27}$

In our study, the main diagnostic category out of 14 different possible ones displaying an increase during 
Table 4 Maternal risk factors for antenatal obstetric hospitalizations in Denmark 2003-20I2

\begin{tabular}{|c|c|c|c|c|}
\hline Maternal risk factors & $\begin{array}{l}\text { Pregnancies with } \\
\text { AOH, n (\%) }\end{array}$ & $\begin{array}{l}\text { Pregnancies without } \\
\text { AOH, n (\%) }\end{array}$ & Crude OR $(95 \% \mathrm{Cl})$ & Adjusted $^{\mathrm{a}}$ OR $(95 \% \mathrm{Cl})$ \\
\hline Overall (pregnancies) & $48,366(8)$ & $569,540(92)$ & & \\
\hline \multicolumn{5}{|l|}{ Maternal age (years) } \\
\hline$<20$ & $\mathrm{I}, \mathrm{I} 84(\mathrm{I} 4)$ & $7,522(86)$ & $1.98(1.85-2.10)$ & $1.22(1.13-1.32)$ \\
\hline $20-24$ & $6,826(10)$ & $58,280(90)$ & $1.47(1.43-1.52)$ & $1.16(1.11-1.20)$ \\
\hline $25-29$ & $14,533(7)$ & $182,335(93)$ & 1 & 1 \\
\hline $30-34$ & $15,880(7)$ & $211,088(93)$ & $0.94(0.92-0.97)$ & $1.04(1.02-1.07)$ \\
\hline $35-39$ & $8,047(8)$ & $92,998(92)$ & $1.09(1.06-1.12)$ & $1.19(1.15-1-23)$ \\
\hline $40+$ & $1,856(10)$ & $|6,48|(90)$ & $1.4 \mid(1.34-1.49)$ & $1.48(1.39-1.57)$ \\
\hline \multicolumn{5}{|l|}{ Parity } \\
\hline Nulliparous & $23,421(9)$ & $248,5 \mid 4(9 I)$ & $1.23(1.20-1.25)$ & $1.24(1.21-1.26)$ \\
\hline Multiparous & $24,288(7)$ & $315,649(93)$ & 1 & 1 \\
\hline \multicolumn{5}{|l|}{ Pregnancy } \\
\hline Singleton & $44,215(7)$ & $55,9710(93)$ & I & I \\
\hline Multiple & $4,151(30)$ & $9,830(70)$ & $5.35(5.15-5.55)$ & $5.50(5.27-5.73)$ \\
\hline \multicolumn{5}{|l|}{ Body mass index $\left(\mathrm{kg} / \mathrm{m}^{2}\right)$} \\
\hline$<18.5$ & $2,977(9)$ & $29,857(91)$ & $1.36(1.31-1.42)$ & $1.26(|.20-| .31)$ \\
\hline $18.5-24.9$ & $21,609(7)$ & $295,047(93)$ & 1 & 1 \\
\hline $25-29.9$ & $8,961(8)$ & $101,420(92)$ & $1.21(1.18-1.24)$ & $1.16(1.13-1.19)$ \\
\hline $30+$ & $6,904(11)$ & $56,360(89)$ & $1.67(1.63-1.72)$ & $1.56(1.51-1.60)$ \\
\hline \multicolumn{5}{|l|}{ Education (years) } \\
\hline$<10$ & $\mathrm{II}, 50 \mathrm{I}(\mathrm{II})$ & $88,219(89)$ & $2.00(1.95-2.05)$ & $1.66(1.60-1.72)$ \\
\hline $10-12$ & $9,440(8)$ & $102,772(92)$ & I.4I (I.37-I.45) & $1.29(1.25-1.33)$ \\
\hline $13-14$ & $\mathrm{II}, 740(7)$ & $144,630(93)$ & $1.24(1.21-1.28)$ & $1.19(1.16-1.22)$ \\
\hline $15+$ & $13,667(6)$ & $209,26 \mathrm{I}(94)$ & 1 & 1 \\
\hline \multicolumn{5}{|l|}{ Working status } \\
\hline Working & $34,943(7)$ & $446,262(93)$ & I & I \\
\hline Unemployed & $2,631(9)$ & $27,909(91)$ & $1.20(1.16-1.26)$ & $1.04(0.99-1.1 \mathrm{I})$ \\
\hline Outside workforce & $10,530(10)$ & $90,962(90)$ & $1.48(|.45-| .5 \mid)$ & $1.25(1.21-1.29)$ \\
\hline \multicolumn{5}{|l|}{ Smoking status } \\
\hline Nonsmoker & $39,509(7)$ & $490,44 \mid(93)$ & I & I \\
\hline Smoker & $7,187(10)$ & $67,627(90)$ & $1.32(1.29-1.35)$ & $1.47(1.37-1.56)$ \\
\hline \multicolumn{5}{|l|}{ Partner status } \\
\hline Cohabitant with partner & $39,750(7)$ & $494,242(93)$ & I & I \\
\hline Single status & $8,239(11)$ & $69,329(89)$ & I.48 (I.44-I.52) & $1.24(1.20-1.28)$ \\
\hline
\end{tabular}

Note: adjustment for all variables in the model including year of admission.

Abbreviations: $\mathrm{AOH}$, antenatal obstetric hospitalizations; $\mathrm{Cl}$, confidence interval; OR, odds ratio.

the study period was the diagnostic group of maternal diseases. The reason for this trend is probably a change in coding practice and increased use of O99.8, which is a nonspecific code of pregnancy complications. Either the registration practice of pregnancy-related hospitalizations has changed during the study period or an increased number of women with comorbidities become pregnant, leading to complications that necessitate inpatient care. A recent review points out that changes in classification systems and diagnostic criteria may hamper the interpretation of temporal trends in incidence. ${ }^{24}$ On the other hand, improved medical treatments over the past decades, along with improved techniques of assisted reproduction, may explain some of the increase in $\mathrm{AOH}$ due to maternal diseases.
Higher age and BMI in pregnant women may also explain some of the increase. A recent Danish registry study demonstrated that the prevalence of pregnant women over 40 years increased from $2.0 \%$ in $2000-2002$ to $3.5 \%$ in $2011-2012$ $(P<0.001)$. Likewise, the prevalence of severe maternal obesity (BMI above $35 \mathrm{~kg} / \mathrm{m}^{2}$ ) increased from $3.6 \%$ in $2003-2005$ to $4.4 \%$ in $2011-2012(P<0.001){ }^{28}$

In a study population presumably with increased maternal age and higher BMI, our finding of increased inpatient care for women with medical comorbidities could be the result of better chances for women with a medical illness to conceive over the study period. The prevalence of women undergoing assisted fertility treatments in Denmark increased by $17 \%$, from 2,409 women in 1998 to 2,816 in $2005 .{ }^{24,29}$ In the year $2010,8 \%$ of all deliveries 
in Denmark had been achieved by assisted fertility treatments. ${ }^{30}$ A Cochrane review from 2013 points out that one in six couples encounter fertility problems, and that an increasing number of pregnancies are achieved from assisted reproductive technology. ${ }^{31}$

The diagnostic category "threatened preterm delivery" explained $31 \%$ of all AOHs, with a slight decrease during the study period. Within this diagnostic category, there was an increased proportion of women with an ultrasonic-identified short cervix and women with preterm contractions. This may be due to changes toward more specific coding practices, as the broad and less specific diagnosis threatened preterm birth O472 decreased simultaneously.

Furthermore, the decrease in the total number of $\mathrm{AOH}$ in the main diagnostic category "threatened preterm delivery" may indicate a general change in the way these pregnancy complications are managed. During the study period, the prevalence of very preterm deliveries stayed stable at approximately $1.5 \%$.

Our results suggest several maternal characteristics as risk factors for $\mathrm{AOH}$. Maternal age and multiple pregnancies were identified previously in studies of risk factors for antenatal hospitalizations. Also, low education level is associated with increased risk of hospitalization among women in general. ${ }^{1,3,4,32}$ The risk factors for $\mathrm{AOH}$ identified in our study confirm that not only may pregnancies be complicated by biological and lifestyle factors, such as maternal age, parity, plurality, BMI, and smoking status, but may also have a social disparity. ${ }^{33-37}$ This is in accordance with a previous study demonstrating that women with poor social support were more often recommended for $\mathrm{AOH}$ by health care professionals. ${ }^{38}$

Register-based studies may have limitations such as the study duration being too short to identify a specific trend. ${ }^{39}$ Moreover, there may be interventions such as activity restrictions during hospitalization that are not registered, even though it could have implications for the course of the pregnancy in women with, for example, threatened preterm delivery.

The results from registry-based data need consideration relative to the quality and validity of these registries. ${ }^{40}$ Our study results are primarily based on data from the Danish Medical Birth Registry and the National Registry of Patients. Systematic validation projects in the obstetric field of these Danish registries have only been applied to selected conditions and cover different periods. ${ }^{40} \mathrm{~A}$ general validation of the National Registry of Patients from 2003 indicates that the validity is good for many well-defined obstetric indicators, whereas other less well-defined areas, like pain relief during labor, need improvement. ${ }^{41}$

We do not know to what extent $\mathrm{AOH}$ implied restriction of physical activities, or if the woman would have been better off with a normal level of physical activity. So far, in regard to threatened preterm delivery, it has not been possible to identify any beneficial effect of strict activity restriction during pregnancy for mother or baby. ${ }^{8,9,13}$ In addition, physical activity during pregnancy is associated with a reduced risk of preterm delivery before $37 \mathrm{com}$ pleted weeks. ${ }^{22}$ Activity restriction is often prescribed in cases of threatened preterm delivery; however, it is not registered with a specific treatment code in any of the Danish registries. ${ }^{12,38,42}$ Thus, it is not possible to explicitly study the extent of pregnancy-related activity restriction at Danish hospitals within obstetric services. Even though the $\mathrm{AOH}$ rate as well as the number of antenatal threatened preterm delivery hospitalizations decreased, many pregnant women still endure activity restriction either during AOHs or at home without a documented beneficial effect of such an intervention. . $^{8,13,43}$

On the other hand, $\mathrm{AOH}$ may be essential for specific complications that cannot be managed on an outpatient basis. Close professional observation may be important to initiate timely and appropriate intervention. Therefore, the question of whether outpatient management is preferable to hospitalization should be determined at an individual level. ${ }^{43}$ However, in the nonacute phase of an antenatal complication, when close daily observations are indicated, there are options for safe outpatient management using telemonitored medicine. ${ }^{38,44}$

Our findings support the call for a randomized controlled trial to evaluate whether activity restriction in complicated pregnancies reduces the risk of preterm delivery., ${ }^{9,45}$ This could be done in women undergoing $\mathrm{AOH}$, as they are at risk of activity restriction and have a higher risk of very preterm delivery.

\section{Conclusion}

We observed a time trend toward fewer and shorter antenatal hospitalizations. More than one-third of the pregnancies with $\mathrm{AOH}$ resulted in a very preterm delivery. The largest diagnostic group was threatened preterm delivery, and in $15 \%$ of these pregnancies, the delivery was very preterm. Significant maternal risk factors for antenatal hospitalization were maternal age and BMI, nulliparity, multiple pregnancies, fewer years of education, being outside the workforce, single partnership, and smoking. 


\section{Acknowledgments}

This study was supported by Research grants from Nordsjaellands Hospital, Hillerod, University of Copenhagen, Denmark; TrygFonden; Lundbeckfonden; and the Danish Association of Midwives.

\section{Disclosure}

The authors report no conflicts of interest in this work.

\section{References}

1. Badgery-Parker T, Ford JB, Jenkins MG, Morris JM, Roberts CL. Patterns and outcomes of preterm hospital admissions during pregnancy in NSW, 2001-2008. Med J Aust. 2012;196(4):261-265.

2. Badgery-Parker T, Shand AW, Ford JB, Jenkins MG, Morris JM, Roberts CL. Multifetal pregnancies: preterm admissions and outcomes. Aust Health Rev. 2012;36(4):437-442.

3. Bennett TA, Kotelchuck M, Cox CE, Tucker MJ, Nadeau DA. Pregnancyassociated hospitalizations in the United States in 1991 and 1992: a comprehensive view of maternal morbidity. Am J Obstet Gynecol. 1998;178(2):346-354.

4. Liu S, Heaman M, Sauve R, et al. An analysis of antenatal hospitalization in Canada, 1991-2003. Matern Child Health J. 2007;11(2):181-187.

5. Rostad B, Schei B. Factors predicting antenatal hospital admission in pregnancy. Scand J Prim Health Care. 1998;16(2):85-89.

6. Turnbull DA, Wilkinson C, Gerard K, et al. Clinical, psychosocial, and economic effects of antenatal day care for three medical complications of pregnancy: a randomised controlled trial of 395 women. Lancet. 2004;363(9415):1104-1109.

7. Aleman A, Althabe F, Belizan J, Bergel E. Bed rest during pregnancy for preventing miscarriage. Cochrane Database Syst Rev. 2005;(2):Cd003576.

8. Crowther CA, Han S. Hospitalisation and bed rest for multiple pregnancy. Cochrane Database Syst Rev. 2010;(7):Cd000110.

9. Elliott JP, Miller HS, Coleman S, et al. A randomized multicenter study to determine the efficacy of activity restriction for preterm labor management in patients testing negative for fetal fibronectin. J Perinatol. 2005;25(10):626-630.

10. Gulmezoglu AM, Hofmeyr GJ. Bed rest in hospital for suspected impaired fetal growth. Cochrane Database Syst Rev. 2000;(2):Cd000034.

11. Maloni JA. Antepartum bed rest for pregnancy complications: efficacy and safety for preventing preterm birth. Biol Res Nurs. 2010;12(2):106-124.

12. Sciscione AC. Maternal activity restriction and the prevention of preterm birth. Am J Obstet Gynecol. 2010;202(3):232. e231-235.

13. Sosa C, Althabe F, Belizan J, Bergel E. Bed rest in singleton pregnancies for preventing preterm birth. Cochrane Database Syst Rev. 2004;(1):Cd003581.

14. Kovacevich GJ, Gaich SA, Lavin JP, et al. The prevalence of thromboembolic events among women with extended bed rest prescribed as part of the treatment for premature labor or preterm premature rupture of membranes. Am J Obstet Gynecol. 2000;182(5):1089-1092.

15. Promislow JH, Hertz-Picciotto I, Schramm M, Watt-Morse M, Anderson JJ. Bed rest and other determinants of bone loss during pregnancy. Am J Obstet Gynecol. 2004;191(4):1077-1083.

16. Brandao KL, Mottola MF, Gratton R, Maloni J. Bone status in activityrestricted pregnant women assessed using calcaneal quantitative ultrasound. Biol Res Nurs. 2013;15(2):205-212.

17. Bendix J, Kjaergaard H, Zoffmann V. Pregnant women's management of activity restriction during hospitalisation: a question of yielding and not feeling deprived of a sense of control. JNeonatal Nurs. 2014;20:24-30.

18. Maloni JA, Brezinski-Tomasi JE, Johnson LA. Antepartum bed rest: effect upon the family. J Obstet Gynecol Neonatal Nurs. 2001;30(2):165-173.
19. Maloni JA, Kane JH, Suen LJ, Wang KK. Dysphoria among high-risk pregnant hospitalized women on bed rest: a longitudinal study. Nurs Res. 2002;51(2):92-99.

20. Rubin M. The physiology of bed rest. Am J Nurs. 1988;88(1):50-56.

21. Downs DS, Chasan-Taber L, Evenson KR, Leiferman J, Yeo S. Physical activity and pregnancy: past and present evidence and future recommendations. Res Q Exerc Sport. 2012;83(4):485-502.

22. Hegaard HK, Hedegaard M, Damm P, Ottesen B, Petersson K, Henriksen TB. Leisure time physical activity is associated with a reduced risk of preterm delivery. Am J Obstet Gynecol. 2008;198(2):180. e181-e185.

23. Hegaard HK, Pedersen BK, Nielsen BB, Damm P. Leisure time physical activity during pregnancy and impact on gestational diabetes mellitus, pre-eclampsia, preterm delivery and birth weight: a review. Acta Obstet Gynecol Scand. 2007;86(11):1290-1296.

24. Schmidt M, Schmidt SA, Sandegaard JL, Ehrenstein V, Pedersen L, Sorensen HT. The Danish National Patient Registry: a review of content, data quality, and research potential. Clin Epidemiol. 2015;7:449-490.

25. World Health Organisation. International Statistical Classification of Diseases and Related Health Problems 10th Revision (ICD-10) Version for 2010. Available from: http://apps.who.int/classifications/icd10/ browse/2016/en\#/XV. Accessed May 1, 2016.

26. Olsen J, Melbye M, Olsen SF, et al. The Danish National Birth Cohort - its background, structure and aim. Scand J Public Health. 2001;29(4):300-307.

27. Public Health Agency of Canada. What Mothers Say: The Canadian Maternity Experiences Survey. Ottawa, Canada: Public Health Agency of Canada; 2009. Available from: http://www.phac-aspc.gc.ca/rhs-ssg/ pdf/survey-eng.pdf. Accessed July 20, 2014.

28. Hedegaard M, Lidegaard O, Skovlund CW, Morch LS, Hedegaard M. Perinatal outcomes following an earlier post-term labour induction policy: a historical cohort study. Br J Obstet Gynaecol. 2015;122(10):1377-1385.

29. Sundhedsstyrelsen. IVF-behandlinger i Danmark 1998-2005. 2007 [The Danish Health Authority. IVF (in Vitro Fertilization) treatments in Denmark 1998-2002. 2007]. Available from: http://sundhedsstyrelsen. dk/publ/tidsskrifter/nyetal/pdf/2007/14_07.pdf. Accessed September 28, 2014. Danish.

30. Sundhedsstyrelsen. Fertilitetsbehandlinger 2010. 2012 [The Danish Health Authority. Fertility treatments 2010. 2012]. Available from: https://stps.dk/da/udgivelser/2012/ /media/E8FC80BA99F14573AE6BE7649381503F.ashx. Accessed September 28, 2014. Danish.

31. Farquhar C, Rishworth JR, Brown J, Nelen WL, Marjoribanks J. Assisted reproductive technology: an overview of Cochrane Reviews. Cochrane Database Syst Rev. 2013;8:Cd010537.

32. Davidsen M, Koch MB, Juel K. Social ulighed i indlæggelser. 2013 [Social inequality in hospital admissions. 2013]. Available from: https:// sundhedsstyrelsen.dk/da/nyheder/2013/ /media/122F19FC1C8147EB 8184D09BF98CC3E4.ashx. Accessed September 28, 2014. Danish.

33. Cedergren MI. Maternal morbid obesity and the risk of adverse pregnancy outcome. Obstet Gynecol. 2004;103(2):219-224.

34. Nilsen AB, Waldenstrom U, Hjelmstedt A, Rasmussen S, Schytt E. Characteristics of women who are pregnant with their first baby at an advanced age. Acta Obstet Gynecol Scand. 2012;91(3):353-362x.

35. Salihu HM, Wilson RE. Epidemiology of prenatal smoking and perinatal outcomes. Early Hum Dev. 2007;83(11):713-720.

36. Shrim A, Ates S, Mallozzi A, et al. Is young maternal age really a risk factor for adverse pregnancy outcome in a Canadian tertiary referral hospital? J Pediatr Adolesc Gynecol. 2011;24(4):218-222.

37. Young BC, Wylie BJ. Effects of twin gestation on maternal morbidity. Semin Perinatol. 2012;36(3):162-168.

38. Bendix J, Hegaard HK, Bergholt T, Langhoff-Roos J. Recommendations of activity restriction in high-risk pregnancy scenarios: a Danish national survey. J Perinat Med. 2015;43(4):429-438.

39. Sorensen HT, Sabroe S, Olsen J. A framework for evaluation of secondary data sources for epidemiological research. Int J Epidemiol. 1996;25(2):435-442. 
40. Langhoff-Roos J, Krebs L, Klungsoyr K, et al. The Nordic medical birth registers - a potential goldmine for clinical research. Acta Obstet Gynecol Scand. 2014;93(2):132-137.

41. Langhoff-Roos J, Rasmussen S. Validering af Landspatientregisteret (LPR) med henblik på obstetrisk forskning og kvalitetssikring. 2003 [Validation of the National Patient register regarding use for obstetric research and quality improvement. 2003]. Available from: http://sundhedsstyrelsen.dk/publ/Publ2003/LPR.pdf. Accessed August 4, 2014. Danish.

42. Fox NS, Gelber SE, Kalish RB, Chasen ST. The recommendation for bed rest in the setting of arrested preterm labor and premature rupture of membranes. Am J Obstet Gynecol. 2009;200(2):165 e161-166.
43. The Royal College of Obstetricians and Gynaecologists. Preterm Prelabour Rupture of Membranes. 2006/2010. Green-top Guideline no. 44. Available from: https://www.rcog.org.uk/globalassets/documents/guidelines/gtg44pprom28022011.pdf. Accessed September 28, 2014.

44. Magann EF, McKelvey SS, Hitt WC, Smith MV, Azam GA, Lowery CL. The use of telemedicine in obstetrics: a review of the literature. Obstet Gynecol Surv. 2011;66(3):170-178.

45. Grobman WA, Gilbert SA, Iams JD, et al. Activity restriction among women with a short cervix. Obstet Gynecol. 2013;121(6): $1181-1186$.
Clinical Epidemiology

\section{Publish your work in this journal}

Clinical Epidemiology is an international, peer-reviewed, open access, online journal focusing on disease and drug epidemiology, identification of risk factors and screening procedures to develop optimal preventative initiatives and programs. Specific topics include: diagnosis, prognosis, treatment, screening, prevention, risk factor modification,

Submit your manuscript here: https://www.dovepress.com/clinical-epidemiology-journal

\section{Dovepress}

systematic reviews, risk and safety of medical interventions, epidemiology and biostatistical methods, and evaluation of guidelines, translational medicine, health policies and economic evaluations. The manuscript management system is completely online and includes a very quick and fair peer-review system, which is all easy to use. 